Gazi University
Journal of Science
$\mathrm{http}: / /$ dergipark.gov.tr/gujs

\title{
The Spherocrystals in the Tubule Epithelial Cells and Ultrastructure of the Malpighian Tubules of Adult Isophya nervosa (Orthoptera, Tettigoniidae)
}

\author{
Damla AMUTKAN MUTLU *(iD), Zekiye SULUDERE \\ Gazi University, Faculty of Science, Department of Biology, 06500 Ankara, Turkey
}

\section{Highlights}

- The ultrastructure of the Malpighian tubules (MTs) of Isophya nervosa was examined.

- Different shapes of spherocrystals were observed in the MTs cells.

- SEM-EDX analysis of the spherocrystals was conducted.

- Differences and similarities of the MTs in Isophya nervosa with other species were revealed.

Article Info

Received: $19 / 02 / 2020$ Accepted: 11/04/2020

\section{Keywords}

Elemental analysis SEM-EDX

Spherocrystal

Excretory system Histology

\begin{abstract}
The excretory system in insects consists of Malpighian tubules (MTs) which are responsible for osmoregulation. The functions of the MTs are the removal of the last products of metabolism and the transfer of the toxic compounds into the hindgut. The MTs of the insects vary structurally. In this study, the MTs of Isophya nervosa Ramme, 1951, which is a species that belongs to Orthoptera order, were investigated by light and electron microscopes. Adult individuals of Isophya nervosa were collected in Kizılcahamam, Ankara in 2017 and 2018. Extracted MTs were fixed in Formaldehyde for light microscopy, in glutaraldehyde for electron microscopes. They were examined and photographed after dehydration, blocking, sectioning and staining processes were completed. This species has a great number of MTs. One end of the MTs in this species is attached to the ileum and the other closed end is free in hemolymph. The outer surface of the cells is surrounded by muscle layers and trachea. There are microvilli on the apical region of cells. The lumen is covered with a monolayer cuboidal epithelium. Numerous concentrically layered spherocrystals in different shapes were observed in the cells. When the chemical compositions of these spherocrystals were analyzed by SEM-EDX system, it was seen that the contents of them were different ions such as iron $(\mathrm{Fe})$, carbon $(\mathrm{C})$, phosphorus $(\mathrm{P})$, magnesium $(\mathrm{Mg})$, sulfur $(\mathrm{S})$, calcium $(\mathrm{Ca})$, and manganese $(\mathrm{Mn})$.
\end{abstract}

\section{INTRODUCTION}

Removal of metabolic wastes from the body is called excretion. The main excretory substances in insects are excess water, salt, nitrogen wastes and some other harmful organic compounds [1]. The insect excretion system consists of Malpighian tubules (MTs) which extend freely in the hemolymph [2, 3]. The MTs work together with the hindgut to remove waste products from the body [4]. The MTs are the excretory organs which are responsible for the removal of nitrogenous waste products regulating the ionic composition of hemolymph and osmoregulation in insects. They are specialized for the transport, metabolism and detoxification of organic dissolved substances [3, 5-11].

MTs also provide minerals that are stored in the form of spherocrystals [12]. Spherocrystals have various functions in insects. In general, they are thought to regulate the protection of the mineral composition of the digestive system, the deposition of toxic metals and of non-toxic waste materials that cannot be metabolized [13]. Spherocrystals, which are deposits of waste materials and store them as vesicles, are found in many insects' digestive system and MTs cells, MTs lumen or gut lumen [14]. They are concentrically layered membrane-bound cytoplasmic structures [15]. The formation of spherocrystal, 
which are formed by the cisternae of the rough endoplasmic reticulum, is a method of excreting large amounts of intracellular deposits in a condensed form with little loss of water $[16,17]$.

Roeder and College (1953) [18] reported that the MTs in insects can be generally divided into different groups. In many insects, the Malpighian system consists of a great number of tubules with the blind-end free in hemolymph and the other end connected to the midgut-hindgut junction of the digestive tract $[3,5$, $6,10,13,19-22]$. In some insect species, the MTs can be connected directly to the digestive tract through the rectum [21]. This special arrangement of the MTs is known as cryptonephridial system. This structure is present in some species of Lepidoptera, Neuroptera, Diptera, Symphita, and Coleoptera orders [12, 18, $23,24]$.

The MTs generally consist of two different segments. Distal and proximal tubules appear to be morphologically different in some species. The distal segment is the secreting part of the MTs, that is, it carries electrolyte, organic solids, and water from the hemolymph to the tubule lumen. The proximal segment is the reabsorption part of the MTs and reabsorbs substances and water [3, 5, 6, 19, 21, 25].

The number of the MTs varies among insect orders and species. There are four MTs in the insects of Diptera order, six MTs in Lepidoptera order, 50-60 MTs in Odonata order. This number can be two orfour MTs in Hemiptera order and 2-200 MTs in Hymenoptera order. The tubule number may be more than 200 in individuals of Orthoptera order [1, 2, 6, 7, 10, 24-27].

Isophya nervosa Ramme, 1951 (Orthoptera, Tettigoniidae) is an endemic species in Turkey. The MTs of Isophya nervosa have been chosen as the subject of this study because no previous studies, to the best of our knowledge, have investigated internal system of this species. For this reason, we aimed to obtain information about the structure and chemical composition of spherocrsytals in the excretory system cells. In addition, the cytology, histology and ultrastructure of excretory system were examined and the similarities and differences between MTs structures of other insect and that of Isophya nervosa were revealed.

\section{MATERIAL METHOD}

\subsection{Material}

Adult individuals of Isophya nervosa were collected in Kizılcahamam, Ankara Province, Turkey from May to August 2017 and 2018. In the laboratory, bush-crickets were kept in plastic boxes and were fed on fresh plants.

\subsection{Preparation of Samples for Stereomicroscope}

The digestive canals in conjunction with MTs of the individuals of Isophya nervosa were dissected in sodium phosphate buffer using Olympus SZX7 stereomicroscope and the photos of the dissected regions were taken with imaging system.

\subsection{Preparation of Samples for Light Microscopy (LM)}

The MTs, which were removed from the alimentary canal were fixed in Formaldehyde. After washing and the dehydration process, samples were embedded in paraffin. 5-7 micron thick sections were taken by using Microm HM 310 microtome. Thereafter, the sections were stained with Hematoxylin and Eosin (H\&E) and Mallory's trichrome stain. The specimens were examined using Olympus BX51 light microscope and were photographed with Olympus E330 camera.

\subsection{Preparation of Samples for Scanning Electron Microscopy (SEM)}

MTs obtained from adult individuals of Isophya nervosa were prepared for scanning electron microscope studies. Dissected samples were fixed in 5\% glutaraldehyde ( $\mathrm{pH} 7.2$, phosphate-buffered). The samples 
were rinsed three times with phosphate buffer. Then dehydration stage was completed in ascending series of ethyl alcohol. Thereafter, the samples were put in amyl acetate twice. After that, the samples were dried by using $\mathrm{CO}_{2}$ with critical point drying apparatus (Polaron CPD 7501 Critical Point Dryer). The specimens (as whole or broken) were mounted with double sided adhesive band on the stubs. The surface of the specimens was coated with gold in a Polaron SC 502 sputter coater to prevent from shining. Examinations of the samples were conducted with a JEOL JSM 6060 LV SEM at an accelerating voltage of 5-10 kV and photos were taken at different magnifications. For elemental analysis, dissected MTs were examined with Scanning Electron Microscope (SEM) fitted with EDX. An EDX analysis of the granules in MTs cells was also conducted.

\subsection{Preparation of Samples for Transmission Electron Microscopy (TEM)}

Dissected tissues were fixed in 5\% glutaraldehyde ( $\mathrm{pH} 7.2$, phosphate-buffered). Post-fixation was performed using $1 \% \mathrm{OsO}_{4}$. The samples were rinsed three times with phosphate buffer for removing the $\mathrm{OsO}_{4}$. Dehydration was performed using a graded ethyl alcohol series. The tissues were embedded in Araldite. The Araldite blocks were sectioned using Leica EM UC6 ultramicrotome. Ultra-thin sections were stained with lead citrate and uranyl acetate. Finally, the stained sections were analyzed using JEOL JEM 1400 TEM at $80 \mathrm{kV}$ in the Electron Microscopy Laboratory of the Faculty of Science at Gazi University, in Ankara Province, Turkey.

\section{RESULTS}

Isophya nervosa has a large number of the MTs, one end of them is joined to the digestive tract at the junction of the midgut and the hindgut, and the other end of them is closed and extends freely in hemolymph. It was observed that the MT number of four individuals, two males and two females, ranges from 80 to 100 tubules (Figures 1,2). The stereomicroscope images show that the MTs are brown in color, long and do not show external segmentation or bead structure (Figure 1). It is seen that each tubule consists of a single layer of cells surrounding a blind-ending lumen in the light microscope (Figures 3a, $3 b$ ). Generally, there is big nucleus in the center of the cells (Figures 3a, 3b, 4). There are a vast number of long microvilli in the apical side of the cells, facing the lumen (Figures 3-5). In the basal regions of the epithelial cells, there are numerous basal membrane infoldings that allow greater absorption (Figure 6). The outer surface of the MTs is covered with muscle layer (Figure 6).

There are two different type of cells in the MTs of Isophya nervosa in TEM sections (Figure 7). The first type of cell is more in number and larger than the other. Therefore, the first type of cell is called as principal cell, the second type of cell is called as stellate cell. Stellate cells, however, have a lower number of granules in the cytoplasm than that of principal cells. A number of mitochondria and numerous concentrically layered spherocrystals in different shapes appear to be present in the cytoplasm of the stellate cells (Figure 7). All of them are in a sac surrounded by membrane (Figures 8-10). Many spherocrystals consist of electron-lucent layers between lamellae of different electron-dense layers. Some spherocrystals are composed of intense concentric mineralized layers appearing as electron-dense regions (Figure 8). Some of them consist of compact electron-dense in central and enclosing electron-lucent regions (Figures 9, 10). While in another case, several spherocrystals, which are round shaped, concentric or compact, can be found in the same membrane. These consist of a non-intense granule in central, and electron-lucent regions follow it, and they are surrounded by many concentric layers of homogeneously distributed electron-dense (Figure 10).

The chemical composition of these spherocrystals, which were obtained using SEM-EDX, involves high rate of iron $(\mathrm{Fe})$ elements. Carbon $(\mathrm{C})$ and phosphorus $(\mathrm{P})$ elements follow up this data. It was found that magnesium $(\mathrm{Mg})$, sulfur $(\mathrm{S})$, calcium $(\mathrm{Ca})$, manganese $(\mathrm{Mn})$ elements are in small quantities (Figure 11).

The nuclei of the stellate cells are round shaped and the membrane of the nucleus has too much indentation. The heterochromatin region of the nucleus is quite apparent in this cell type, too. Microvilli on the apical surface of the stellate cells are either absent or do not appear in our sections (Figure 7). 
Various types of granules are found in the cytoplasm of the principal cells (Figures 7, 12). There are also long microvilli in the apical side of the cells (Figures 5, 7). Lateral membrane folds are also clearly evident in the principal cells (Figure 12). The nuclei of these cells are ovoid shape. The heterochromatin region of the nucleus is pretty dense (Figures 7,12 ).

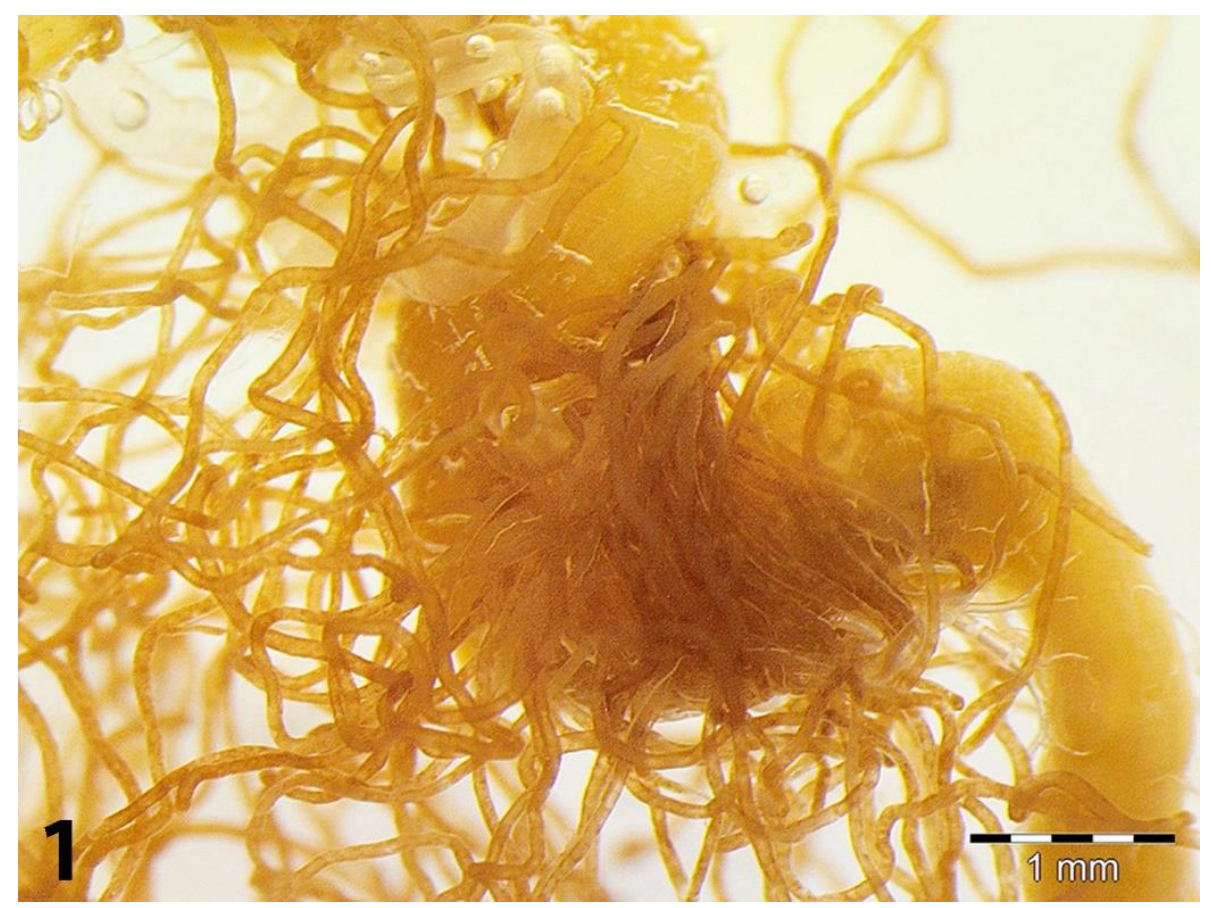

Figure 1. The general view of the Malpighian tubules in Isophya nervosa (Stereomicroscope)

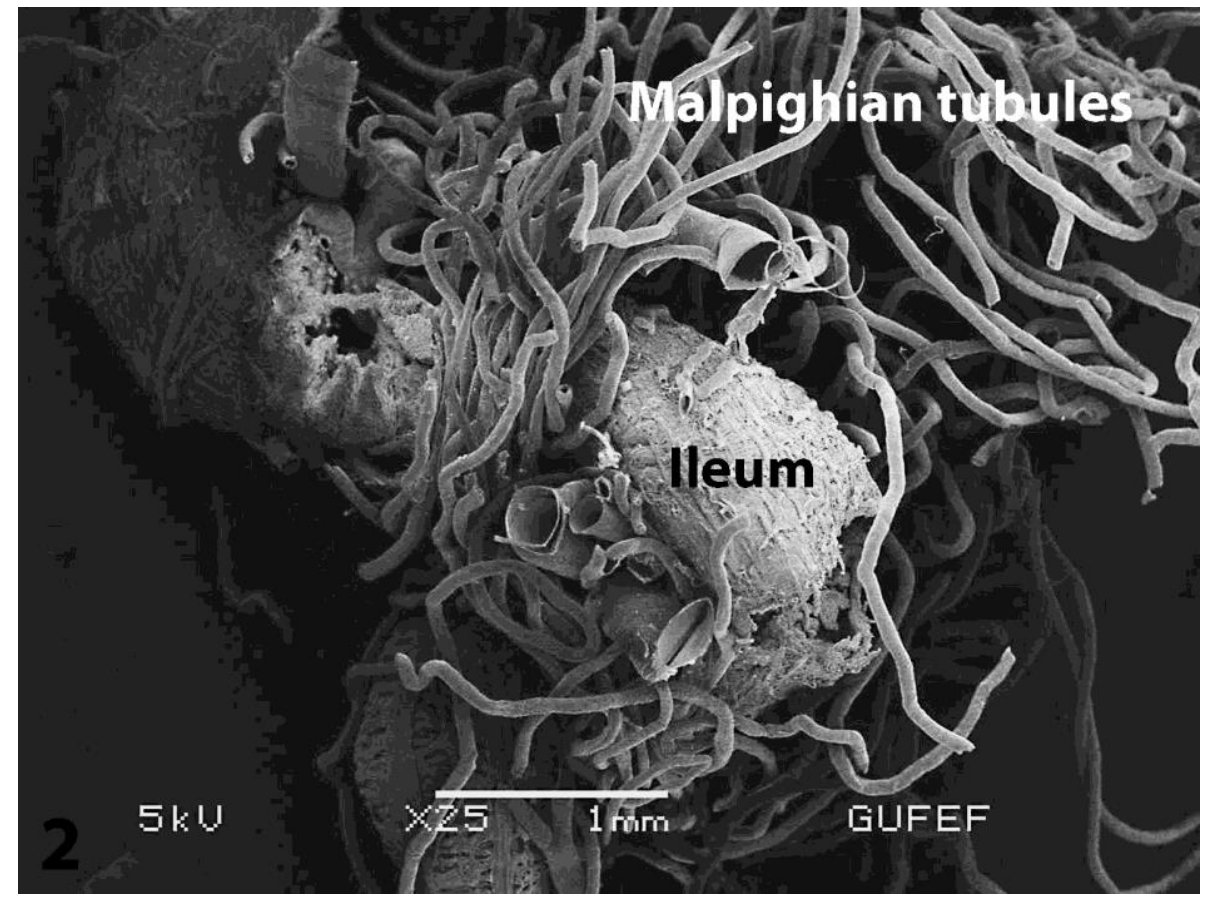

Figure 2. The general view of the Malpighian tubules in Isophya nervosa (SEM) 


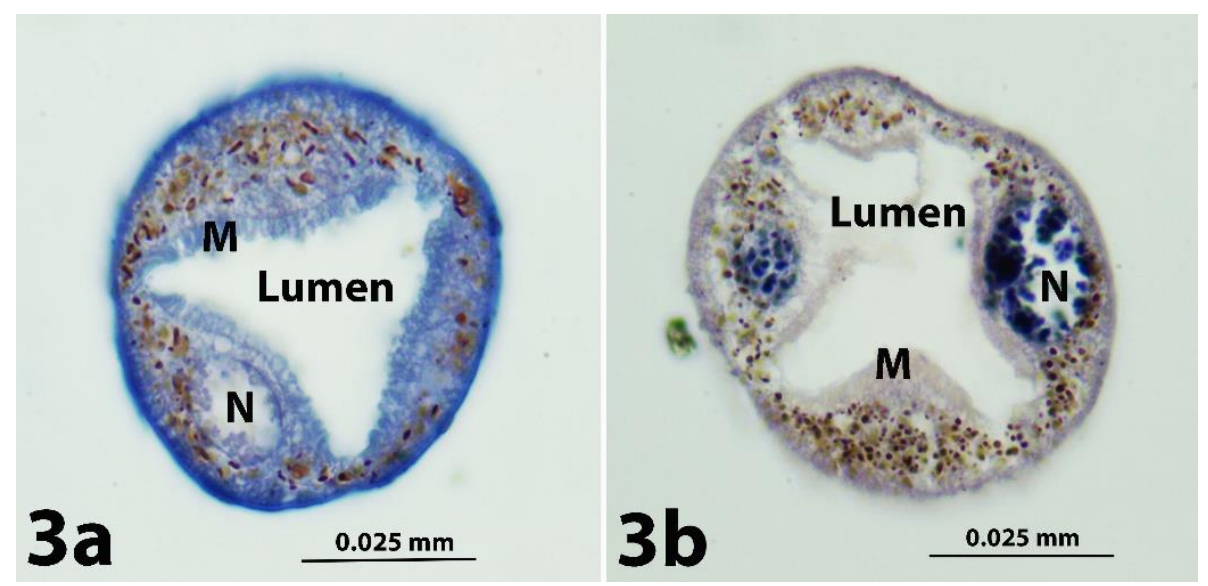

Figure 3. (a) The cross section of the Malpighian tubules. Nucleus (N), microvilli (M) (LM, Mallory's trichrome stain, X1000), (b) The cross section of the Malpighian tubules. Nucleus (N), microvilli (M) (LM, H\&E, X1000)

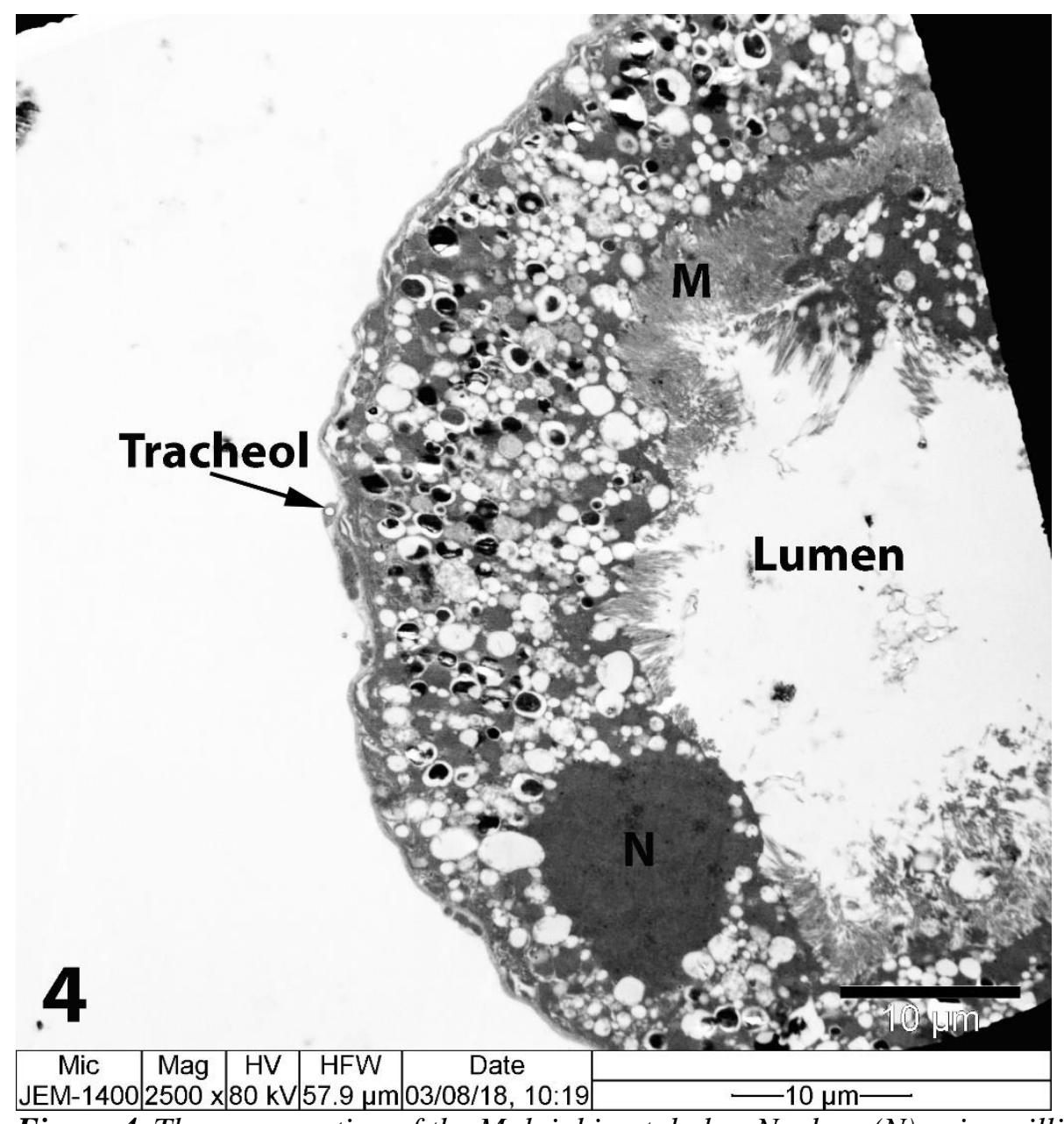

Figure 4. The cross section of the Malpighian tubules. Nucleus (N), microvilli (M) (TEM) 


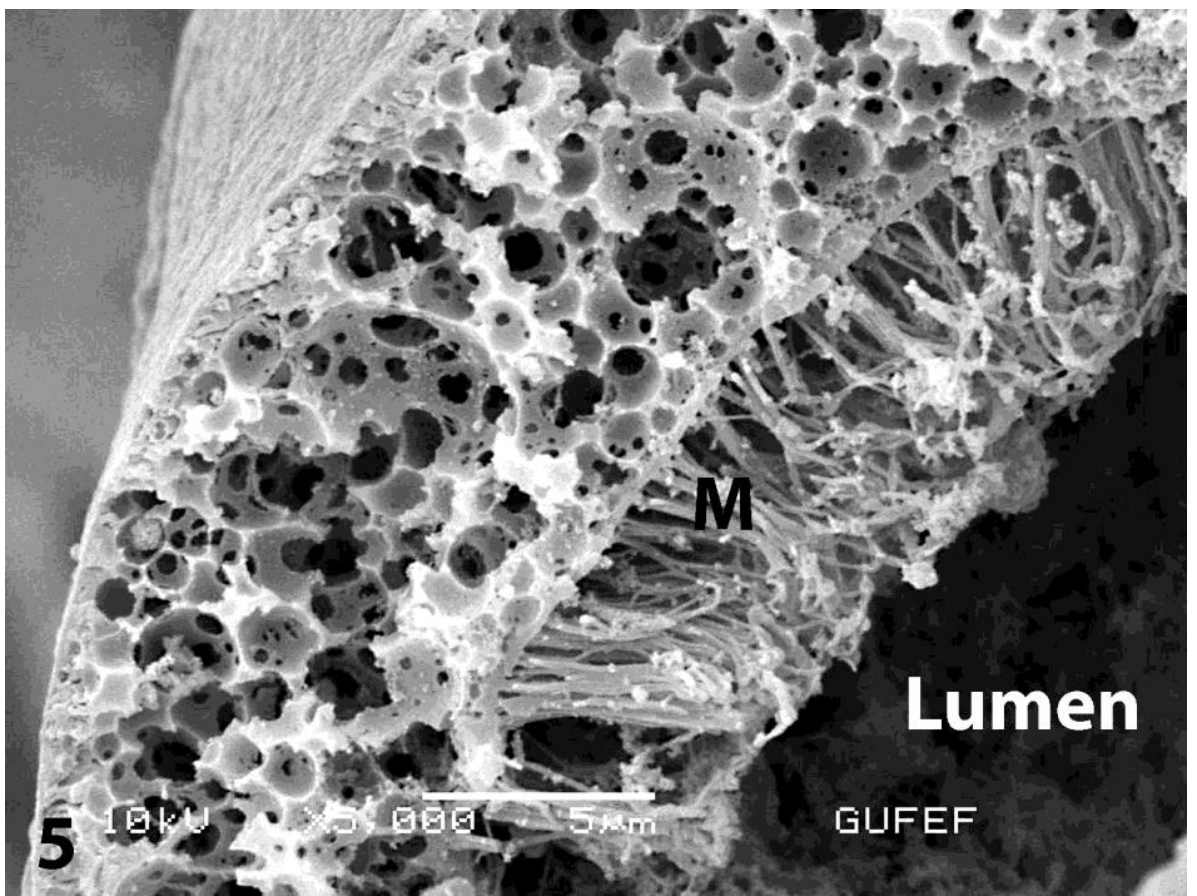

Figure 5. The cross section of the Malpighian tubules and microvilli (M) (SEM)

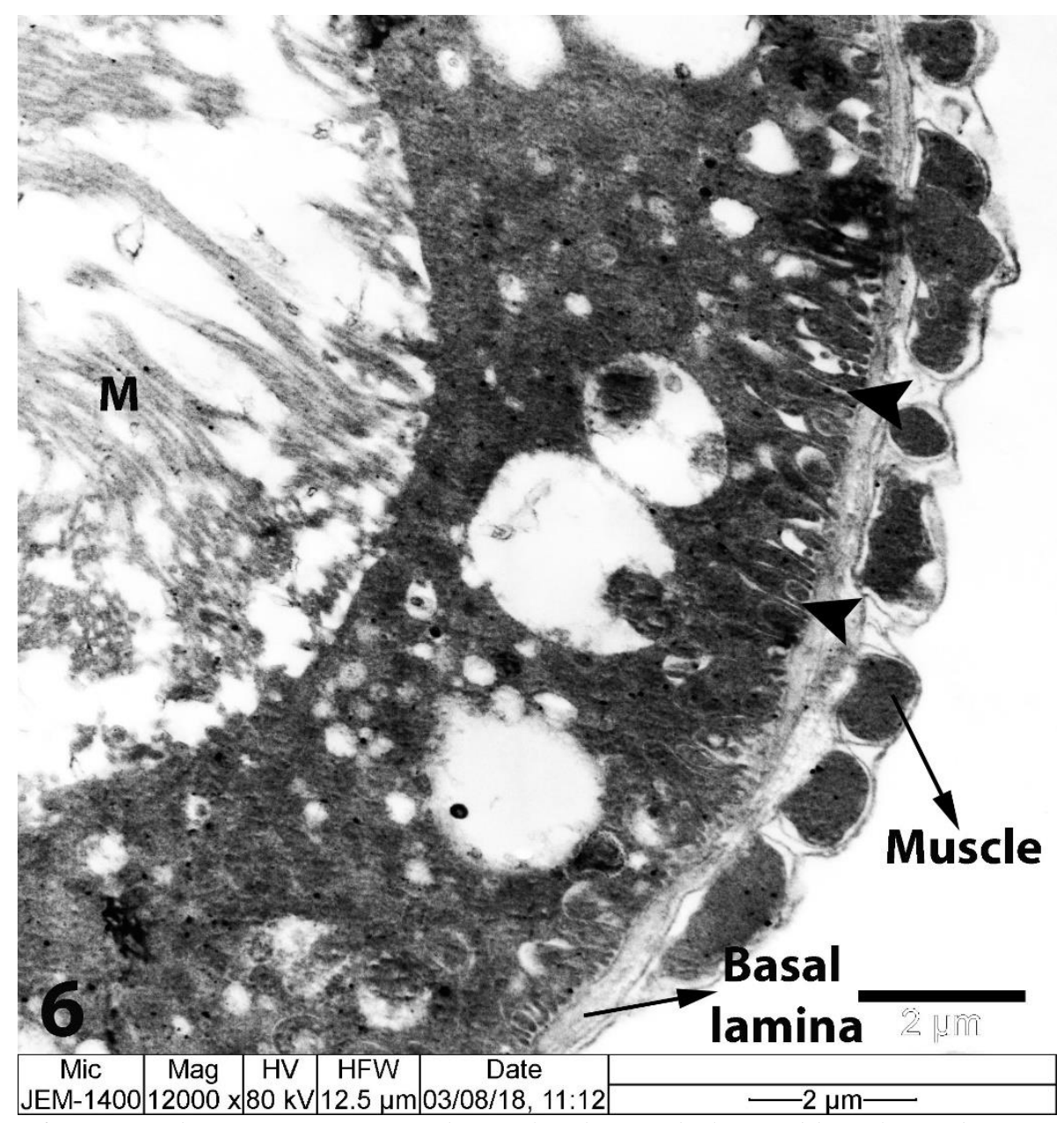

Figure 6. The cross section of the Malpighian tubules and basal membrane infoldings (arrowhead), microvilli $(M)(T E M)$ 


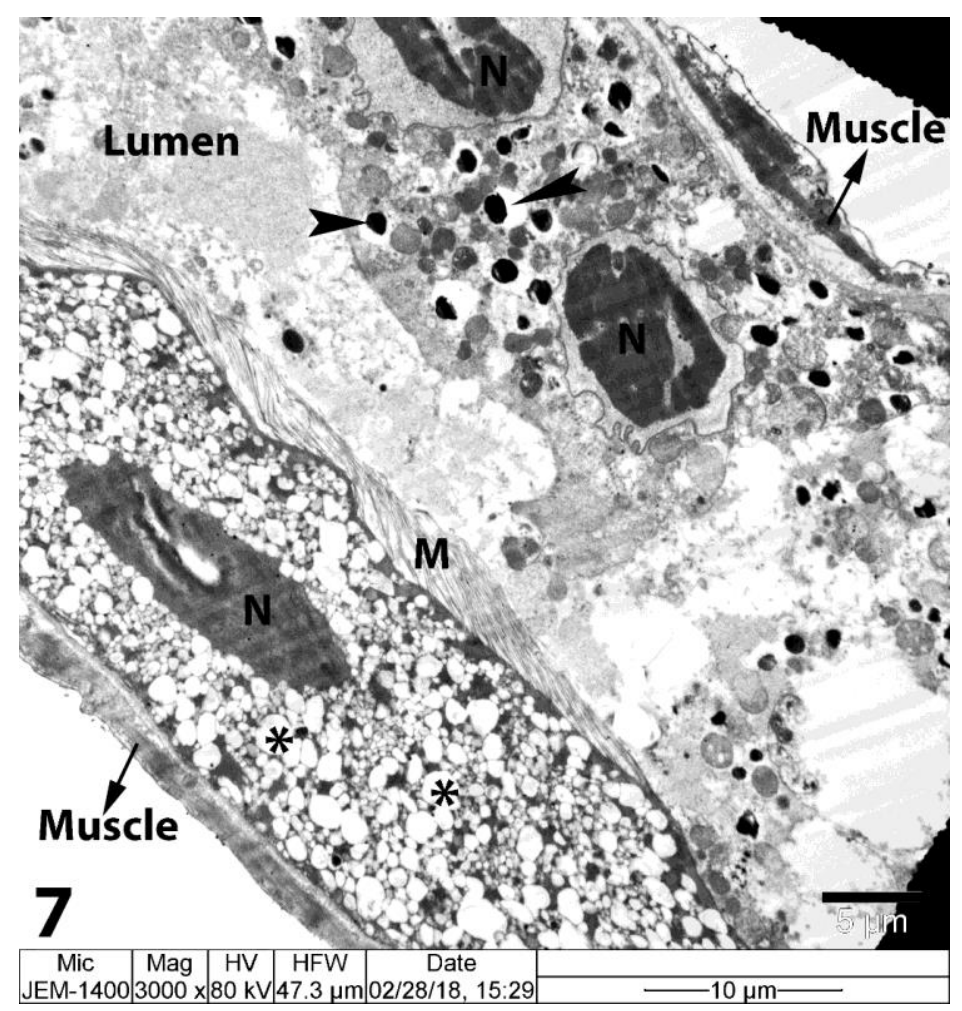

Figure 7. The longitudinal section of the Malpighian tubules. The heterochromatin region of the nucleus is quite dense in two types of cells. Nucleus $(N)$, microvilli $(M)$ of the principal cell, granules (*), spherocrystals (arrowhead) of the stellate cell (TEM)

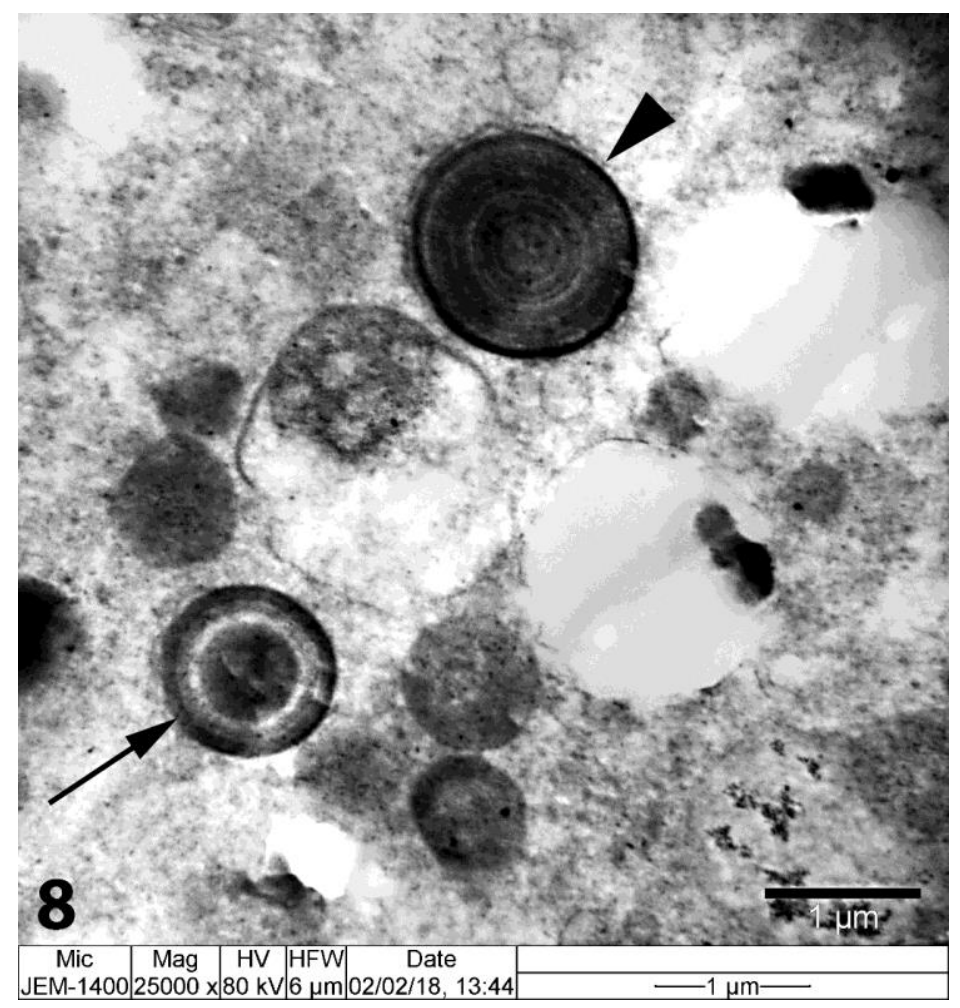

Figure 8. TEM photograph of the spherocrystals which have electron-lucent layers between lamellae of different electron-dense layers $(\rightarrow)$ and spherocrystals which have intense concentric mineralized layers appearing as electron-dense regions (-) 


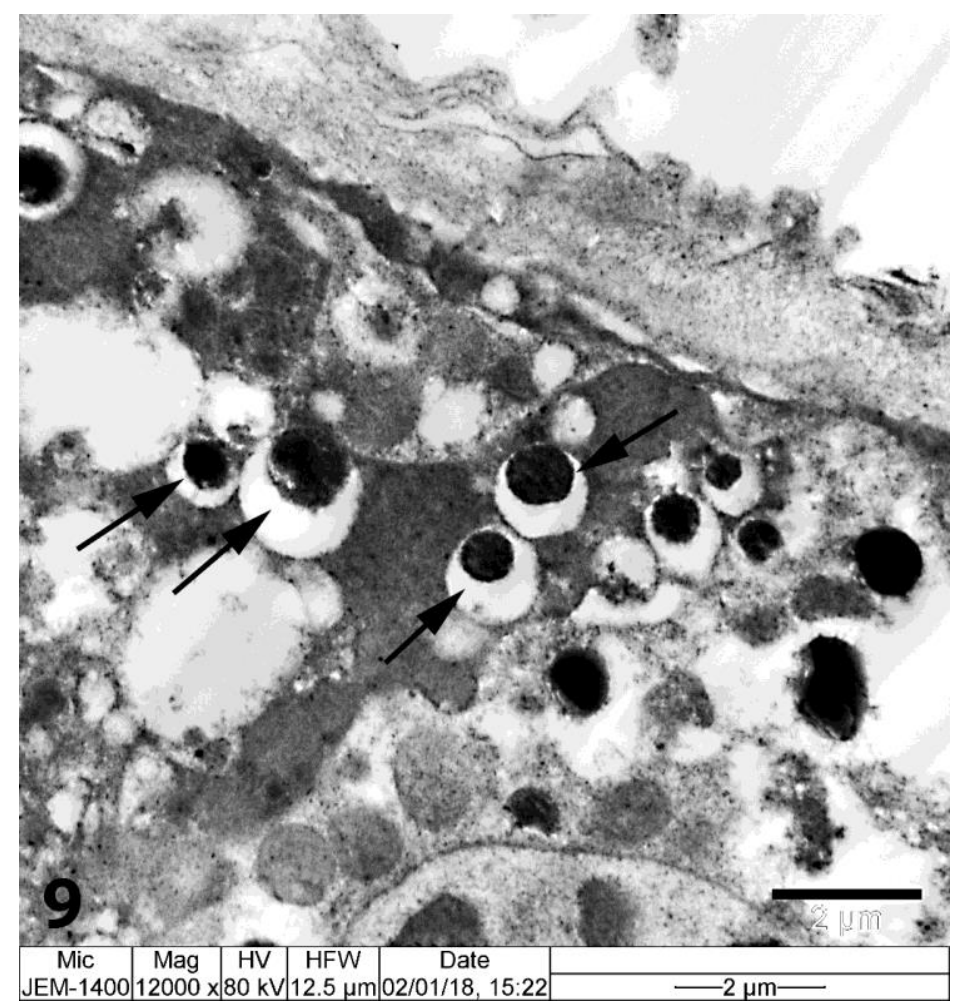

Figure 9. TEM photograph of the spherocrystals which have compact electron-dense in central and enclosing electron-lucent regions $(\rightarrow)$

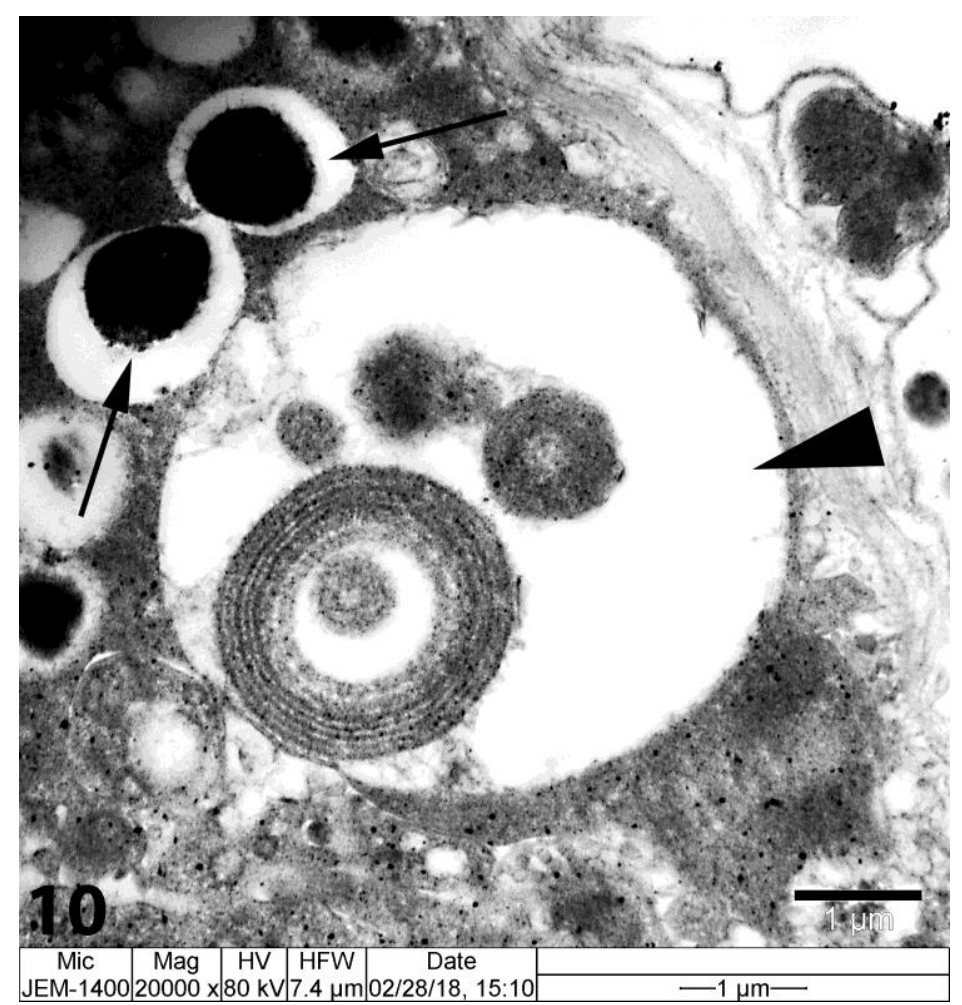

Figure 10. TEM photograph of the spherocrystals which have compact electron-dense in central and enclosing electron-lucent regions $(\rightarrow)$, spherocrystals which are round shaped, concentric or compact in the same membrane ( $)$ 


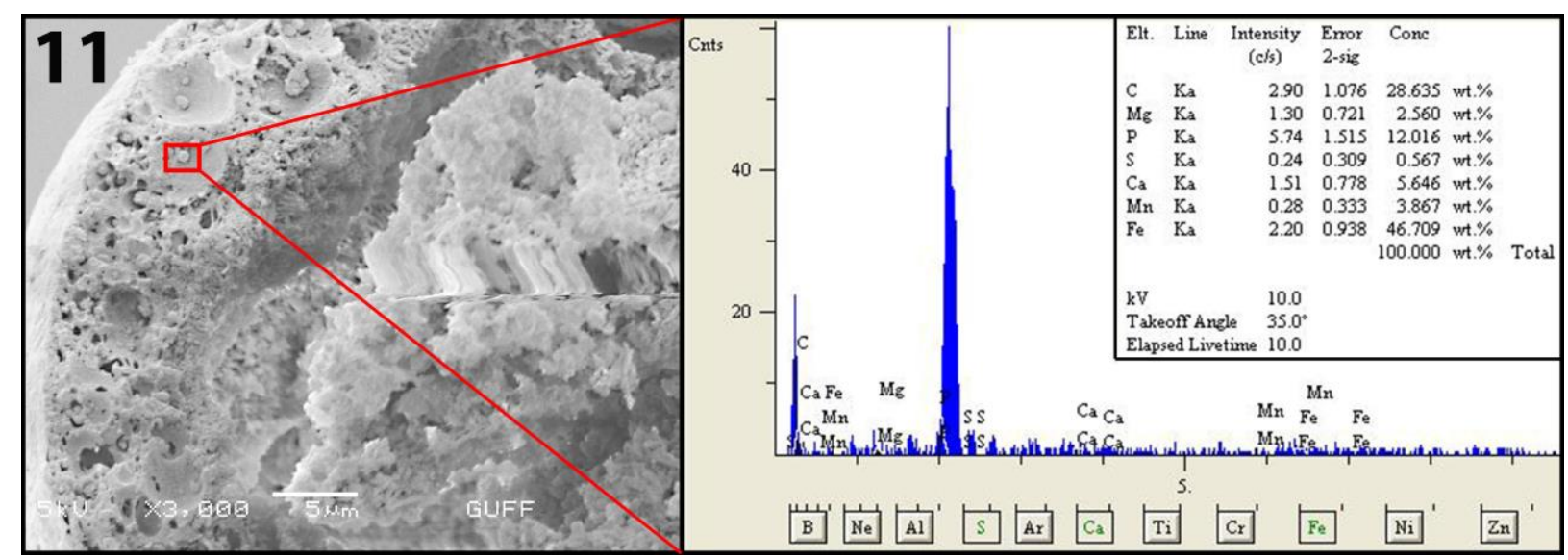

Figure 11. The chemical composition of spherocrystals which were obtained using SEM-EDX

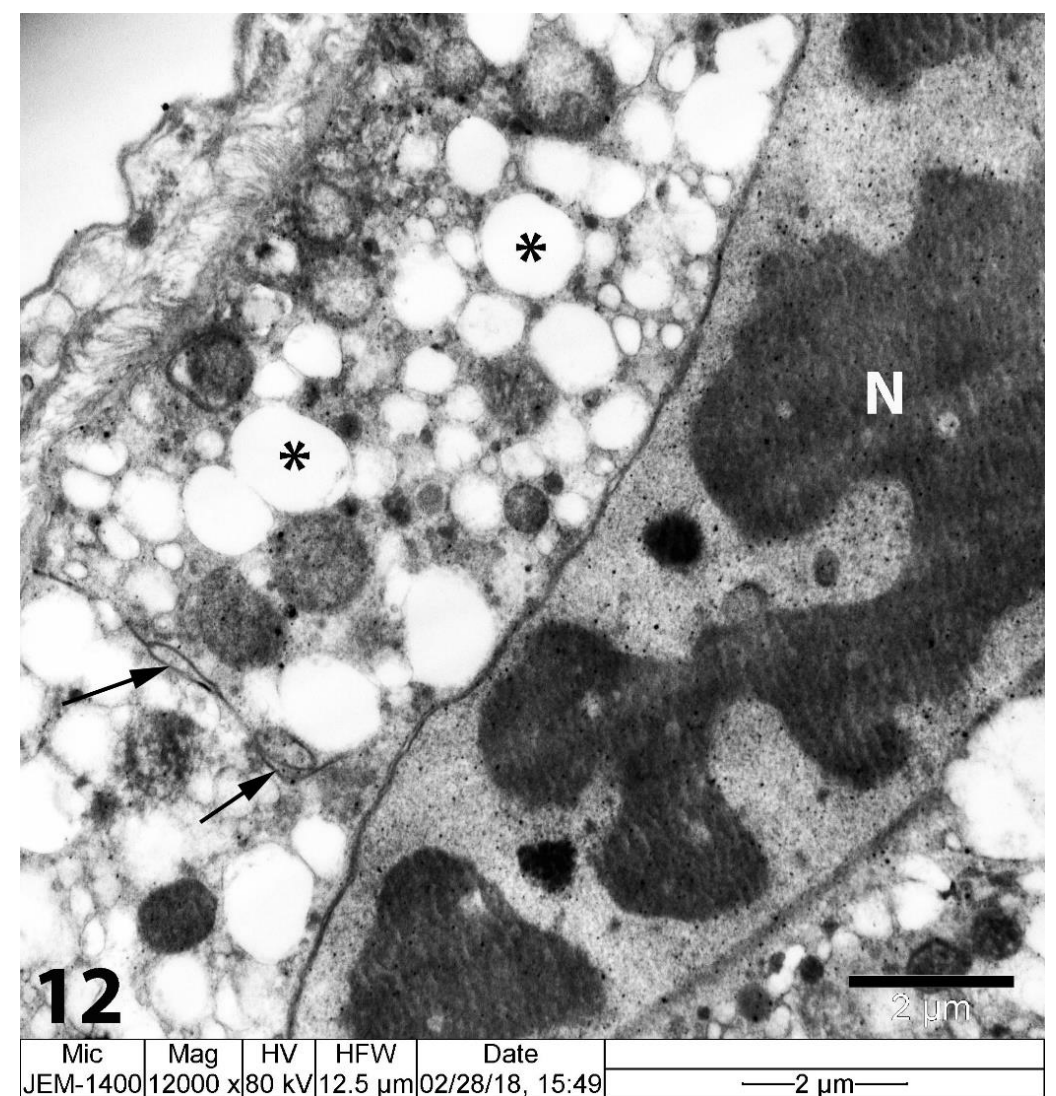

Figure 12. The longitudinal section of the principal cell. Nucleus $(N)$, granules $(*)$, lateral membrane folds (arrow) (TEM)

\section{DISCUSSION}

Malpighian tubules, which are responsible for excretion, are the organs in the excretory system. They are generally found on the junction point of the midgut and the hindgut. However, the MTs are directly connected with the hindgut in some insect species [1, 9, 24, 28, 29]. Along with basic similarities, the structure and number of the MTs varies considerably among insect classes. The MTs, which generally extend freely in the body cavity, are in contact with certain parts of the digestive canal in some species $[27,28,30,31]$. The MTs are connected to the digestive tract at the junction of the midgut and the hindgut in many insect species as in Rhodnius prolixus (Hemiptera, Reduviidae) [21], Drosophila melanogaster (Diptera, Drosophilidae) [3], Troglophilus neglectus (Orthoptera, Rhaphidophoridae) [13] and Poecilimon cervus (Orthoptera, Tettigoniidae) [10]. The distal end is free in the body cavity in these species. Conversely, the MTs are directly linked to the hindgut in the system which is known as the 
cryptonephridial system. In Onymacris plana plana (Coleoptera), Arachnocampa luminosa (Diptera) and Rhodnius prolixus (Heteroptera), the distal ends of the MTs extend to the rectum [21, 31, 32]. There is no cryptonephridal system in Isophya nervosa. MTs extend freely in the body cavity.

The number of tubules varies between insect species although most occur in multiples of two. The tubule number in Graphosoma lineatum, which belongs to Heteroptera order, is four as two pairs [25]. There are about 150 tubules in each individual in Periplaneta americana (Blattodea) [33]. This number is approximately 14-24 tubules in Grylloblatta compodeiformis (Orthoptera, Grylloblattidae) [6]. The number of MTs of Schistocerca gregaria (Orthoptera) is 250 tubules [2]. In adult Isophya nervosa, the number of MTs has been observed to vary from 80 to 100. This number is a lower range than it is in other Orthopteran species.

In a number of insects, there is a remarkable regional specialization of the MTs. The MTs have two segments as proximal and distal segment in Dysdercus koenigi (Hemiptera, Pyrrhocoridae), Triatoma infestans (Heteroptera, Reduviidae), Rhodnius prolixus (Heteroptera) and Graphosoma lineatum (Heteroptera, Pentatomidae) [21, 25, 34, 35]. The MTs of Troglophilus neglectus (Orthoptera, Rhaphidophoridae) and Solenopsis saevissima (Hymenoptera, Formicidae) consist of three regions: proximal, middle and distal segments [13, 24,36$]$. The MTs of Aedes taeniorhynchus (Diptera, Culicidae) and Poecilimon cervus (Orthoptera, Tettigoniidae) do not split into distinct segments [10,24]. In a similar manner, the MTs of Isophya nervosa, that have a large number of tubules, show no visible differences over their entire length of the tubules.

The tubules of Isophya nervosa consist of a monolayered epithelium, which includes two cell types such as large principal cells and small stellate cells. The presence of two cell types has been reported in the MTs of Terrobittacus implicatus (Mecoptera, Bittacidae) [37]. It was also reported that MTs of Carausius morous (Phasmida) [38], Aedes taeniorhynchus (Diptera) [39], Culex pipiens pallens (Diptera) [40] and Aedes aegypti (Diptera) [26] were composed of two types of cells [41]. On the other hand, Calliphora erythrocephala (Diptera) [42] was classified into four types of cells. These types of cells are rather different in ultrastructure [41].

Great number of granules and numerous spherocrystals were observed inside the cytoplasm of the tubule cells in Isophya nervosa. These spherocrystals, which are commonly called as laminate spheres, spherites or mineral concretions, are generally supposed to serve as a form of storage excretion [12]. These spherocrystrals have a concentric content reported in cells of many insect internal systems [13, 43, 44]. They are always associated with a specific cell type. The spherocrystals are found in the principal cell of the MTs in Aedes taeniorhynchus (Diptera) and Periplaneta americana (Blattodea) [12, 33, 39]. However, in Terrobittacus implicatus, the principal cells of the MTs have numerous spherocrystals [37]. While the stellate cells in Isophya nervosa are characterized by a wide range of spherocrystals, there were no spherocrystals observed in the tubule cells of Anopheles sinesis (Diptera) [41].

Spherocrystals are dynamic structures because the number of spherocrystals increase all the way through insect aging and these accumulate in the cytoplasm of the cells. It is suggested that the spherocrystals released by secretion is a detoxification mechanism in the cells [14]. Spherocrystals are generally found in MTs cells and midgut cells of insects [13, 15, 25, 43, 45-49]. They can contain different elements such as calcium $(\mathrm{Ca})$, magnesium $(\mathrm{Mg})$, potassium $(\mathrm{K})$, phosphorus $(\mathrm{P})$, manganese $(\mathrm{Mn})$, iron $(\mathrm{Fe})$, zinc $(\mathrm{Zn})$, and chlorine $(\mathrm{Cl})$ [16]. These metal or non-metal ions are essential elements for mitochondrial respiration and cuticle formation [50]. These stored elements may vary during larval, pupal, and adult life. For example, although the spherocrystals are found in only larval stage in Euroleon sp. (Neuroptera), they can be present throughout the developmental stage in another Neuropteran Chrysopa sp. [16].

The mineral concretions including zinc $(\mathrm{Zn})$, manganese $(\mathrm{Mn})$ and magnesium $(\mathrm{Mg})$ ions in MTs cells were described in most insect orders such as Orthoptera, Coleoptera, Diptera, and Hymenoptera [16, 48, $51,52,53]$. The storage of the calcium $(\mathrm{Ca})$ and phosphorus $(\mathrm{P})$ in the cells was also reported in some invertebrates such as Androctonus australis (Scorpiones), Coelotes terrestris (Aranea), Gyas annulatus (Opiliones) [47]. It is reported that increasing of the calcium and phosphorus in the spherocrystals 
correlate with the mineralisation of the cuticle [47]. In 1987, Krueger, Broce, and Hopkins [45] reported that although the calcium containing spherocrystals were found in larvae stage, these spherocrystals disappeared after pupation. It is thought that the disappeared calcium ions in the cells pass into the hemolymph and contribute to the process of puparium formation [45]. In 2002, Lipovšek, Letofsky-Papst, Hofer, and Pabst, [47] obtained the same result in Gyas annulatus (Opiliones), too. Similar interpretation is available in another literature [46]. This literature showed that the stored calcium during the larval stage in Musca autumnalis (Diptera) decreased in the course of puparium formation [46]. As a result, it was deduced that the calcium was used for mineralization of puparium [46]. In our study, calcium was seen to a certain extent.

The EDX analysis of the spherocrystals, which is observed in the cytoplasm of the tubule cells in Isophya nervosa, shows that there are large quantities of iron. In the previous studies, it was indicated that the iron is one of the essential elements for the survival of the insect. It is stored as a ferritin molecule in the cell. Ferritin is pretty conspicuous in the midgut and MTs cell. Therefore, ferritin which is found at extremely high levels, confirms that iron is necessary for cellular requirement [54]. The high iron content showed that there is a kind of ferritin storage method [55]. In Drosophila (Diptera), iron existence is related to important developmental signals $[49,56]$. When Drosophila species were compared, it was seen that stored iron amount in MTs changed despite following the same diet [54].

The results of this paper have shown that the ultrastructure of the Malpighian tubule of Isophya nervosa bears close resemblance to the other Orthoptera species. Our findings provide new insights in the structure of the MTs of bush-crickets. It is thought that this study, which elucidated the morphological and histological structure of the MTs of this species, may be the basis for further research. According to the data of the chemical analysis of spherocrystals, MTs are thought to play an important role in the transport of ions and function in homeostatic control.

\section{ACKNOWLEDGEMENT}

We express our thanks to Prof. Dr. Mustafa ÜNAL (Bolu Abant İzzet Baysal University, Faculty of Arts and Sciences, Biology Department) for helping the species diagnosis and to Gazi University Academic Writing and Research Center for their help and support in the proofreading of the current study. This study is a part of Damla AMUTKAN MUTLU's PhD thesis. The Malpighian tubules is presented as an oral presentation in $1^{\text {st }}$ International Eurasian Conference on Biological and Chemical Sciences, 26-27 April 2018 in Ankara, Turkey.

\section{CONFLICTS OF INTEREST}

No conflict of interest was declared by the authors.

\section{REFERENCES}

[1] Acar, G., "Morphology and Histology of Malpighian Tubules of Melanogryllus desertus (Pallas, 1771) (Orthoptera: Gryllidae)", Msc. Thesis, Ege University Institution of Science, İzmir, 1-23, (2009) (in Turkish).

[2] Savage, A.A., "The development of the Malpighian tubules of Schistocerca gregaria (Orthoptera)", Querterly Journal of Microscopical Science, 97(4):599-615, (1956).

[3] Gautam, N.M., Tapadia, M.G., "Overview of Malpighian tubules development and function in Drosophila melanogaster", Journal of Scientific Research, 58:87-98, (2014).

[4] Ramsay, J.A., "The excretory system of the stick insect, Dixippus morosus (Orthoptera, Phasmidae)", Journal of Experimental Biology, 32:183-199, (1955).

[5] Maddrell, S.H.P., "Secretion by the Malpighian tubules of Rhodnius. The movements of ions 
and water", The Journal of Experimental Biology, 51:71-97 (1969).

[6] Jarial, M.S., "Fine structure of Malpighian tubules Grylloblatta compodeiformis (Orthoptera: Grylloblattidae)", Transactions of the American Microscopical Society, 109(4):329-341 (1990).

[7] Gullan, P.J. Cranston, P.S., "Böcekler: Entomolojinin Ana Hatları”. In A. Gök (Ed.). Nobel Yayınevi (2012) (in Turkish).

[8] Pal, R., Kumar, K., "Ultrastructural features of the larval Malpighian tubules of the flesh fly Sarcophaga ruficornis (Diptera: Sarcophagidae)", International Journal of Tropical Insect Science, 32(3):166-172, (2012).

[9] Zhong, H., Zhang, Y., Wei, C., "Morphology and ultrastructure of the Malpighian tubules in Kolla paulula (Hemiptera: Cicadellidae)", Zoologischer Anzeiger-A Journal of Comparative Zoology, 257:22-28, (2015).

[10] Polat, I., "The Ultrastructural Features of the Digestive, Excretory, Female and Male Reproductive Systems of Poecilimon cervus Karabag, 1950”, Ph.D Thesis, Gazi University Institution of Science, Ankara, 1-187, (2016) (in Turkish).

[11] Silva, J.R., Amaral, D.T., Viviani, V.R., "Comparison of the Malpighian tubules and fat body transcriptional profiles of Zophobas morio larvae (Coleoptera: Tenebrionidae)", Comparative Biochemistry and Physiology-Part D, 29:95-105, (2019).

[12] Nocelli, R., Cintra-Socolowski, P., Roat, T., Silva-Zacarin, E., Malaspina, O., "Comparative physiology of Malpighian tubules: form and function”, Insect Physiology, 2016:13-23, (2016).

[13] Delakorda, S.L., Letofsky-Papst, I., Novak, T., Hofer, F., Pabst, M.A., "Structure of the Malpighian tubule cells and annual changes in the structure and chemical composition of their spherites in the cave cricket Troglophilus neglectus Krauss, 1878 (Raphidophoridae, Saltatoria)", Arthropod Structure and Development, 38:315-327, (2009).

[14] Gonçalves, W.G., Fialho, M.D.C.Q., Azevedo, D.O., Zanuncio, J.C., Serrão, J.E., "Ultrastructure of the excretory organs of Bombus morio (Hymenoptera: Bombini): bee without rectal pads", Microscopy and Microanalysis, 20(1):285-295, (2014).

[15] Lipovšek, S., Letofsky-Papst, I., Hofer, F., Pabst, M.A., Devetak, D., “Application of analytical electron microscopic methods to investigate the function of spherites in the midgut of the larval antlion Euroleon nostras (Neuroptera: Myrmeleontidae)", Microscopy Research and Technique, 75(4): 397-407, (2012).

[16] Ballan-Dufrançais, C., "Localization of metals in cells of pterygote insects", Microscopy Research and Technique, 56(6):403-420, (2002).

[17] Fontanetti, C.S., Tiritan, B., Camargo-Mathias, M.I., "Mineralized bodies in the fat body of Rhinocricus padbergi (Diplopoda)", Journal of Morphological Sciences, 23(3-4):487-493, (2006).

[18] Roeder, K.D., College, T., "Insect Physiology". Chapmen\&Hall Ltd, London, 387-407 p, (1953).

[19] Beams, H.W., Tahmisian, T.N., Devine, R.L., "Electron microscope studies on the cells of the Malpighian tubules of the grasshopper (Orthoptera, Acrididae)", The Journal of Biophysical and Biochemical Cytology, 1(3):197-212, (1955). 
[20] Maddrell, S.H.P., "Fluid secretion by the Malpighian tubules of insects", Philosophical Transactions of the Royal Society of London B, 262:197-207, (1971).

[21] Martini, S.V., Nascimento, S.B., Morales, M.M., "Rhodnius prolixus Malpighian tubules and control of diuresis by neurohormones", Annals of the Brazilian Academy of Science, 79(1):8795, (2007).

[22] Giglio, A., Perrotta, I.D., Brandmayr, P., "Exosomes: Ultrastructural evidence in epithelial cells of Malpighian tubules", Micron, 100:34-37, (2017).

[23] Nation, J.L., "Insect Physiology and Biochemistry", New York, CRC Press, 485 p, (2002).

[24] Pacheco, C.A., Alevi, K.C.C., Ravazi, A., de Azeredo Oliveira, M.T.V., "Review: Malpighian tubules, an essential organ for insects", Entomology, Ornithology and Herpetology, 3(2):1-3, (2014).

[25] Amutkan, D., Suludere, Z., Candan, S., "Ultrastructure of digestive canal of Graphosoma lineatum (Linnaeus, 1758) (Heteroptera: Pentatomidae)", Journal of the Entomological Research Society, 17(3):75-96, (2015).

[26] Bradley, T.J., Stuart, A.M., Satir, P., "The ultrastructure of the larval Malpighian tubules of a saline-water mosquito" Tissue and Cell, 14:59-773, (1982).

[27] Chapman, R.F., "The Insects: Structure and Function" 4th ed., Cambridge University Press, London, 770 p, (1998).

[28] Denholm, B., Skaer, H., "Development of the Malpighian Tubules in Insects", In L.I. Gilbert, K. Iatrou, S.S. Gill (Eds.). Comprehensive Molecular Insect Science, UK, University of Cambridge, 291-314 pp, (2005).

[29] Gillott, C., "Entomology”, Springer Science \& Business Media, (2005).

[30] Wigglesworth, V.B., "The Principles of Insect Physiology", Methuen and Co, London, 546 p, (1965).

[31] Bradley, T.J., "The Excretory System, Structure and Physiology" 1st ed., In G.A. Kerkut, L.I. Gilbert (Eds.). Comprehensive Insect Physiology, Biochemistry and Pharmacology, Pergamon Press, London, 421-465 pp, (1985).

[32] Green, L.F.B., "Cryptonephric Malpighian tubule system in a dipteran larva, the New Zealand glow-worm, Arachnocampa luminosa (Diptera: Mycetophilidae): A structural study", Tissue and Cell, 12:41-151, (1980).

[33] Wall, B.J., Oschman, J.L., Schmidt, B.A., "Morphology and function of Malpighian tubules and associated structures in the cockroach, Periplaneta americana", Journal of Morphology, 146(2):265-306, (1975).

[34] Srivastava, U.S., Bahadur, I., "The development of the Malpighian tubules in Dysdercus koenigi (Hemiptera: Pyrrhocoridae)", Quarterly Journal of Microscopical Science, 3(59):347-360, (1961).

[35] Mello, M.L.S., Dolder, H., "Fine structure of the Malpighian tubes in the blood-sucking insect, Triatoma infestans Klug", Protoplasma, 93(2-3):275-288, (1977). 
[36] Arab, A., Caetano, F.H., "Segmental specializations in the Malpighian tubules of the fire ant Solenopsis saevissima Forel 1904 (Myrmicinae): an electron microscopical study", Arthropod Structure \& Development, 30(4):281-292, (2002).

[37] Liu, L., Hua, B.Z., "Ultrastructure of the larval Malpighian tubules in Terrobittacus implicatus (Mecoptera: Bittacidae)", Protoplasma, 255(4):1121-1128, (2018).

[38] Taylor, H.H., "Structure and functional changes in the Malpighian tubules of Carausius morosus during dehydration and starvation", Zeitschrift für Zellforschung und Mikroskopische Anatomie, 141(4):479-492, (1973).

[39] Satmary, W.M., Bradley, T.J., "The distribution of cell types in the Malpighian tubules of Aedes taeniorhynchus (Wiedemann) (Diptera: Culicidae)", International Journal of Insect Morphology and Embryology, 13:209-214, (1984).

[40] Yu, C.H., "Ultrastructure of the Malpighian tubule cells in the mosquito larvae, Culex pipiens pallens", Korean Journal of Entomology, 29:141-147, (1999).

[41] Yu, C.H., "Ultrastructure of the Malpighian tubule cells in the mosquito larvae, Anopheles sinesis", Entomological Research, 33(3):151-159, (2003).

[42] Alkassis, W., Schoeller-Raccaud, J., "Ultrastructure of the Malpighian tubules of blowfly larva, Calliphora erythrocephala Meigen (Diptera Calliphoridae)", International Journal of Insect Morphology and Embryology, 13:215-231, (1984).

[43] Pinheiro, D.D.O., Conte, H., Gregorio, E.A., "Spherites in the midgut epithelial cells of the sugarcane borer parasitized by Cotesia flavipes", Biocell, 32(1):61-67, (2008).

[44] Santos, H.P., Rost-Roszkowska, M., Vilimova, J., Serrão, J.E., "Ultrastructure of the midgut in Heteroptera (Hemiptera) with different feeding habits", Protoplasma, 254(4):1743-1753, (2017).

[45] Krueger, R.A., Broce, A.B., Hopkins, T.L., "Dissolution of granules in the Malpighian tubules of Musca autumnalis Degeer, during mineralization of the puparium", Journal of Insect Physiology, 33(4):255-263, (1987).

[46] Krueger, R.A., Broce, A.B., Hopkins, T.L., Kramer, K.J., "Calcium transport from Malpighian tubules to puparial cuticle of Musca autumnalis", Journal of Comparative Physiology B, 158(4):413-419, (1988).

[47] Lipovšek, S., Letofsky-Papst, I., Hofer, F., Pabst, M.A., "Seasonal-and age-dependent changes of the structure and chemical composition of the spherites in the midgut gland of the harvestmen Gyas annulatus (Opiliones)", Micron, 33(7-8):647-654, (2002).

[48] Stewart, A.D., Anand, R.R., Laird, J.S., Verrall, M., Ryan, C.G., de Jonge, M.D., Paterson, D., Howard, D.L., "Distribution of metals in the termite Tumulitermes tumuli (Froggatt): two types of Malpighian tubule concretion host $\mathrm{Zn}$ and $\mathrm{Ca}$ mutually exclusively", PLoS One, 6(11):1-7, (2011).

[49] Tejeda-Guzmán, C., Rosas-Arellano, A., Kroll, T., Webb, S.M., Barajas-Aceves, M., Osorio, B., Missirlis, F., "Zinc storage granules in the Malpighian tubules of Drosophila melanogaster", BioRxiv, 159558, (2017).

[50] Tejeda-Guzmán, C., Rosas-Arellano, A., Kroll, T., Webb, S. M., Barajas-Aceves, M., Osorio, 
B., Missirlis, F., "Biogenesis of zinc storage granules in Drosophila melanogaster", Journal of Experimental Biology, 221(6):1-13 jeb168419, (2018).

[51] Wessing A, Zierold K., "Metal-salt feeding causes alterations in concretions in Drosophila larval Malpighian tubules as revealed by x-ray-microanalysis", Journal of Insect Physiology, 38(8):623-632, (1992).

[52] Przybyłowicz, W.J., Przybyłowicz, J.M., Migula, P., Głowacka, E., Nakonieczny, M., Augustyniak, M., "Functional analysis of metals distribution in organs of the beetle Chrysolina pardalina exposed to excess of nickel by Micro-PIXE", Nuclear Instruments \& Methods in Physics Research Section B-Beam Interactions with Materials and Atoms, 210:343-348, (2003).

[53] Tylko, G., Borowska, J., Banach, Z., Pyza, E., Przybyłowicz, W.J., Mesjasz-Przybyłowicz, J. "Co-localization of copper, zinc and lead with calcium in their accumulation sites in the housefly's abdomen by micro-PIXE”, Microchimica Acta. 155:301-304, (2006).

[54] Dow, J.A., "The essential roles of metal ions in insect homeostasis and physiology", Current Opinion in Insect Science, 23:43-50, (2017).

[55] Köhler, H.R., Körtje, K.H., Alberti, G., "Content, absorption quantities and intracellular storage sites of heavy metals in Diplopoda (Arthropoda)", BioMetals, 8(1):37-46, (1995).

[56] Llorens, J.V., Metzendorf, C., Missirlis, F., Lind, M.I., "Mitochondrial iron supply is required for the developmental pulse of ecdysone biosynthesis that initiates metamorphosis in Drosophila melanogaster", JBIC Journal of Biological Inorganic Chemistry, 20(8):1229-1238, (2015). 